\title{
Analyzing the Impact of Search Engine Optimization Techniques on Web Development Using Experiential and Collaborative Learning Techniques
}

\author{
Dipti Yogesh Pawade \\ Assistant Professor, Information Technology, K. J. Somaiya College of Engineering, Vidyavihar, Mumbai, India \\ Email: diptipawade@ somaiya.edu
}

Received: 29 March 2020; Accepted: 22 June 2020; Published: 08 April 2021

\begin{abstract}
A well designed website using various search engine optimization (SEO) techniques can help to survive in the competition. Thus, for the students who are likely to be web developer in future; learning the theoretical concept of SEO is not enough. The way in which SEO strategy is being drafted varies as per the purpose of website. Hence along with the concept assimilation, instructor needs to make the student think critically to identify the problem and solve it in best possible way. Hence to explore the board panorama of SEO techniques, experiential and collaborative leaning techniques are used. The main objective of the study is to analyses the impact of these modern techniques on depth of concept assimilation by students. To ascertain the effect of these learning techniques, analytical data of the entire website is analyzed. Also feedback is taken from student to know their perception about the whole process. It has been found that students enjoyed the whole learning process. The analytical data proves that the website performed really well which in turn proves that student got in depth understanding of the concept and they were able to implement it commendably in real world scenario.
\end{abstract}

Index Terms: Search engine optimization, website designing, content optimization, structure optimization, website traffic, experiential learning technique, collaborative learning technique.

\section{Introduction}

Today everyone wants to have their online presence. Because of this there is tremendous increase in the website in all categories. Let us consider the category of E-learning website. There are n number of E-learning websites focusing various streams and subject. Out of them some are interactive, some are static, some required membership to access the content while some are absolutely open to use. As the features provided by each and every website is almost similar, it become highly essential to opt the appropriate strategy to get the highest visibility on search engine. There are two ways to improve the visibility of website on search engine:

- Through Search Engine Optimization (SEO)

- Through Search Engine Marketing (SEM)

SEO is the way to improve the ranking of your website in order to get the highest visibility on search engine as a result of organic search [1][2][3]. On the other hand SEM is implemented through pay per click strategy where search engine gives you top position in search result; in return you need to pay them back for each click.

Looking at the future perspective of SEO, we have included it as an Elective course for VII sem in Department of Information Technology, K. J. Somaiya College of Engineering, Vidyavihar, Mumbai which is an autonomous institute. This subject is introduced in web development stream. Here the undergraduate (UG) students of Information Technology (IT) studies Web programming-I course in IV semester where they learn client side web programming. In $\mathrm{V}$ semester, they studies Web programming-II course where they learn server side web programming and connecting the client and server. Thus after complementing these two courses, students have their complete website in ready to host condition. But again as discussed in the beginning of the introduction, the question is whether these websites are as per the SEO standard? To get answer of this question, student opt for the SEO course. 
The outcomes of course are as follows:

CO1: Apply search engine optimization essentials covering aspects of on-page and off-page optimization to web page.

$\mathrm{CO} 2$ : Comprehend factors influencing search engine optimization.

CO3: Understand how to measure performance of web site from search engine perspective and avoid SEO traps.

The major limitation of the traditional classroom based theoretical teaching is that it leads to passive learning where learner is not actively involved. This seems to be ineffective when it comes to train the technical students to meet the modern industry requirement. Because of passive learning there is gap between education system and industry requirement [4]. According to the Biggs et. al. active learning is an effective medium to bridge this gap [5]. To implement active learning, we have used various online SEO tools and innovative teaching strategies. The practical list is designed such that it consists of various tasks based on the experiential and the collaborative learning.

The major objectives of our study are

Objective 1: To study the influence of implementation of SEO technique on website visibility.

Objective 2: To study how experiential learning and collaborative learning techniques stimulus the concept acclimatization capacity of the students.

From this study, we expect to know that whether the proposed approach is appropriate or not to effectually deliver the content in case of SEO

This paper is structured such that section II gives indication given by different researcher experiential and collaborative learning. Section III gives details about various activities carried out in experiential and collaborative learning. In section IV results have been discussed and finally conclusion is drawn in section V.

\section{Literature Survey}

Experiential learning emphasize on learning by doing [6]. Kolb's model of experiential learning is based on following four pillars:

- Concrete experience,

- Observation and conclusion drawing,

- Abstract concepts formulation and

- Experimentation

It suggests to actively experimenting the abstract concept drawn from the conclusion taken out from the implication of experience [7]. There are many evidences where experiential learning proved as an effective way of content delivery in engineering discipline. Ayob et al. concluded that activities based on experiential learning were helpful to cultivate and improvise student creativity in engineering education [8]. Similar opinion is put forth by Verner et. al.[9]. They opined that experiential learning is the most effective way to understand the engineering concepts. Another researcher Kosnik et. al. observed that entrenches the practical experience directly into the course content enhancing the student's assimilation capacity [10]. Hanh [11] discoursed that the success experiential learning project help the students of Electrical Engineering work hard and persist to elaborate new things. According to the studies performed by Antonio et. al. [12], Bruke [13], Clark et. al. [14] stated that experiential learning is an inquiry-based learning which is motivates critical thinking, problem solving and technology-based learning. In addition to the significance of experiential learning; few researcher have manifested the challenge faced while implementing it. Nooghabi et. al. have identified challenges like inadequate infrastructure, lack of experience and skill set of instructors to device the experiential learning activity effectively, poor class management and passive attitude of learner towards the changed teaching methodology [15]. Yadav et. al. [16], Suckarieh et. al. [17] also raised the concern for of extra effort required to developed modern infrastructure and change traditional teaching styles. This may lead to the resistance from learner as well as instructors side. Osagiede et. al. [18] and Albdeli [19] conferred that learning through experiential model involved lots of time. Hence its applicability in technical curriculum is less flexible. It has been also observed that those who have implemented well defined and thoughtfully designed experiential learning model have achieved the success for vocational courses too [20, 21]. Specifically Stephanus et. al. elaborated the worth of Kolb's experiential learning[22]. They carried out the study for the students of mechanical engineering students and they come to the conclusion that a well planned experiential learning activities can lead to the great success.

Like experiential learning, collaborative learning also enriches critical thinking capability of the students [23][24]. It not only imparts the knowledge but also improves the social interaction between learners and teachers where all share their experience and views to get best possible solution [25]. Thus, every individual student students learns his responsibility for peer group activity results [26]. Through the study carried out by Olga et. al, collaborative learning 
has proven as effective way of learning in engineering discipline[27]. In contrast to this, Mark et. al. [28] derives the conclusion that collaborative learning is nonconductive for the success of the student. The main hurdle in the success of collaborative learning methodology is the resistance and passive participation of the learners. Though through various research, learning from peers is consider as an activity that empowered the student with better understanding [29].

\section{Implementation Overview}

The study proposed in the paper is based on the following research questions:

1. Is there need of implementation of SEO technique for better visibility of website?

2. What is the impact of experiential learning and collaborative learning techniques on concept acclimatization by the student of technological background?

\section{Strategy Overview:}

To make the learning effective and to give insights of various SEO techniques the experiment list was divided into two logical groups:

- The first section was based on the experiential learning. where students actually inspect their website Vs SEO standards, use SEO tools and make SEO compatible website. Along with the experimentation, they have to note down their observation and findings.

- The second section was based on the collaborative learning where each student present their SEO journey. They present their observations, findings, which tool they have used, reason behind choosing the perticular tool and then discusion is carried out among the peers.

\section{Sample Overview:}

For experimental purpose, we have considered total 64 students who have opted this course. The lab is conducted batch wise so these students are divided into three batches of 21,21 and 22 each. All these students had good knowledge of web programming and are well verse with the coding related tags and terminologies. So as a pre-requisite each of them was ready with their website. Weakly a slot of 2 hours is allotted to each batch. Considering the semester of 16 week and looking at possibility of holidays, throughout the semester; on an average 30 hours are available. Table I gives the time allotted for the complete process for each batch.

Table 1. Activity time chart

\begin{tabular}{|l|l|}
\hline Task & $\begin{array}{l}\text { Alloted } \\
\text { Duration } \\
\text { (in Hours) }\end{array}$ \\
\hline Experiancential Learning (Total 20 hours) \\
\hline Hosting of website and setting up Google Analytics & 02 \\
\hline Choosing Correct Keyword & 04 \\
\hline Content and Structure Optimization & 08 \\
\hline Link Optimization & 02 \\
\hline Analyzing Google Analytics Report & 04 \\
\hline Collaborative Learning (Total 10 hours) & 10 \\
\hline Presentations, discussion and modifications & \multicolumn{2}{|l}{} \\
\hline
\end{tabular}

\section{A. Experential Learning}

Initially, every student has to host their website first. Then for tracking the various metrics, set up for Google analytics [30] is done on every website. For setting up Google analytics, students needs to sign up. Once the sign up process is completed students got the unique Javascript code, which need to be added in the head $<>$ section of every page on website. This is called as JavaScript type of tracking. Thus all the activities happening on the website can be tracked using Google analytics. This tool provide the insight to various metrics like number of visitors, geographical location of visitors, new vs repetitive visitors, bounce rate etc. which are further essential to state the SEO process is successful or not. After that actual SEO process is carried out. Figure 1 shows the SEO implementation steps followed by us. 


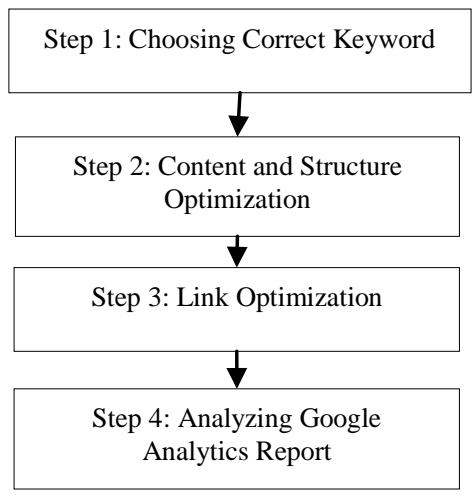

Fig.1. SEO implementation Steps

\section{Choosing Correct Keyword}

Choosing correct keyword plays an important role in the process of search engine optimization. Keywords need to be inline with the content of your web page. The success of SEO planning depends upon how well one chooses the keyword [31]. Initially SEO practioners come up with the list of keywords or keyword phrase. Brainstorming sessions are carried out in order to refine the list. In order to finalize the keyword it is necessary to see the search volume and other parameters like CPC, trend etc. To get these statistics one can use the keyword tool like Moz's Keyword Explorer [32], KWFinder [33], SEMrush [34], Google Keyword Planner[35] etc. Based on the results; minimum 6-10 keywords are finalised for a webpage. Finalised keywords are not repetitive, clearly describe the content of the webpage and have chosen based on the observations of keyword analysis tool.

\section{Content and structure Optimization}

Unique and original content is the key behind the success of your SEO plan. Because even though we implement all the strategy to bring the visitors to the doorstep of your website and the content quality is poor, visitor won't stay on the page [17]. There are few things that one needs to consider while performing content optimization.

- Content need to be unique.

- Strictly adhere to appropriate keyword density

- Avoid the keyword stuffing.

- Web page should not be to large or too short

- Page loading time need to be minimum

- Organize the content properly

- Avoid grammatical or typo mistakes

- Have appropriate title tag with keyword included in title.

- Include keyword in meta description tag

- Presence of keyword in H1 tag

- Take care of keyword prominence

- Include keyword in anchor text

- Use alt attribute in img $<>$ tag

- Include sitemap

- Include robot.txt

The main aim behind content and structure optimization is to design user as well as search engine bot friendly website with quality content.

\section{Link Optimization}

There are three types of links, viz. internal link, outgoing link and incoming link. Internal links are the links between the web pages of same sire. Outgoing links are links present on your webpage and pointing to the other websites. Incoming links are the links from other sites pointing to your site in order to direct users to your web page. Broken links are considered as negative SEO factors. Students need to take care that all the web pages of a website are link to each other in order to provide the smooth navigation. Incoming links are considered as a vote to your website. More the number of incoming links more is your popularity. Initially search engine used to consider the number of incoming links to calculate the page rank of web-page. Thus more the number of incoming links more is your popularity an in tern higher is the page rank. But then most of the studentss started implementing the malpractices like 
buying links, link farming etc. Now-a-days, search engine have eye on such practices and if any website is found to be involved in it, then that web page or web site may lose the ranking or even get banned. Thus studentss need to be very careful while choosing the link strategy. One should always avoid the practice of link farming or link buying. Also the quality of the webpage providing the incoming link to you matters a lot. Incoming link from low quality site is considered as negative factor [36, 37].

\section{Analyzing Google Analytics Report}

Google analytics is basically used for monitoring and analyzing the traffic. You can get statistics related to user's geographical location, their language, screen resolution, from which reference link they visited the website, at what time they visited the website, for how much time they stayed on website, which pages they crawled, from which page they exited etc. All these data is important to understand the visitors behaviour and surfing pattern for the website and thus in turn help us to plan SEO and marketing strategy.

\section{B. Collaborative learning}

As discuss earlier students maintain the log book to note down their findings. Once all the experiments based on the experiential learning are done then each student need to give the presentation. The key points that need to be included are as follows

\section{Choosing Correct Keyword}

- Initial keyword list

- Tool used for Keyword optimization (Specify if any other tool was used initially and that does not work properly in your case study)

- Final keywords (also need to discuss reason behind choosing it)

\section{Content and structure Optimization}

- SEO score for each parameter before implementing SEO guidelines

- Tool used for Content and structure Optimization (Specify if any other tool was used initially and that does not work properly in your case study)

- Final SEO score and major steps that has been carried out to achieve it

\section{Link Optimization}

- Specify the number of inbound, outbound and broken links before implementing Link Optimization

- Tool used for Link Optimization (Specify if any other tool was used initially and that does not work properly in your case study)

- Discuss Link Optimization strategy used

- Specify the number of inbound, outbound and broken links after implementing Link Optimization

\section{Analyzing Google Analytics Report}

- Discuss the reach of your website based upon the various statistics given by Google analytics

- After the presentation, a discussion session carried out for 30-45 min. All the students and instructor is involved in it. They carry out focused discussion exploring the challenges faced during the implementation and possible solutions to it. Student has to make note of techniques discussed in presentations and have to implement it on their own dummy website. Then in next session, their impressions about the tool and techniques is discussed. This can be considered as one of the way to validate and cross verify the things stated of presenter student.

\section{Result Analysis}

To demonstrate the impact of implementation of SEO strategies on the visibility of the website we have experiment it on total 64 websites. Each of this website was having minimum 10 pages. As discussed in the introduction, these websites are developed by the same students in their third year. 
Table 2. Website Analysis before Implementing SEO techniques

\begin{tabular}{|c|c|c|}
\hline Tag/Parameter & Criteria & No of web sites \\
\hline \multirow[t]{4}{*}{ Title <> } & Not present & 23 \\
\hline & Empty tag & 21 \\
\hline & Inappropriately used & 18 \\
\hline & Appropriately used & 02 \\
\hline \multirow{4}{*}{$\begin{array}{l}\text { Meta } \\
\text { description }<>\end{array}$} & Not present & 64 \\
\hline & Empty tag & 0 \\
\hline & Inappropriately used & 0 \\
\hline & Appropriately used & 0 \\
\hline \multirow[t]{3}{*}{ Heading tag <> } & Not present & 08 \\
\hline & $\begin{array}{l}\text { Present in proper hierarchy } \\
\text { with proper content }\end{array}$ & 04 \\
\hline & Randomly present & 52 \\
\hline \multirow[t]{4}{*}{ Anchor $<>$} & $\begin{array}{l}\text { Without proper anchor and link } \\
\text { text }\end{array}$ & 22 \\
\hline & $\begin{array}{l}\text { Without proper anchor text but } \\
\text { with link text }\end{array}$ & 11 \\
\hline & $\begin{array}{l}\text { Without link text but with } \\
\text { random anchor text }\end{array}$ & 30 \\
\hline & $\begin{array}{l}\text { With proper anchor and link } \\
\text { text }\end{array}$ & 01 \\
\hline \multirow[t]{2}{*}{ img<> } & img tag with alt attribute & 17 \\
\hline & img tag without alt attribute & 47 \\
\hline \multirow[t]{5}{*}{ Unique content } & Below 20\% & 13 \\
\hline & $20 \%-35 \%$ & 24 \\
\hline & $36 \%-50 \%$ & 18 \\
\hline & $51 \%-75 \%$ & 06 \\
\hline & Above $75 \%$ & 03 \\
\hline \multirow{2}{*}{$\begin{array}{l}\text { Grammar and } \\
\text { typo mistakes }\end{array}$} & Present & 29 \\
\hline & Not present & 35 \\
\hline \multirow{3}{*}{$\begin{array}{l}\text { Content on web } \\
\text { page }\end{array}$} & Too short & 09 \\
\hline & Moderate & 49 \\
\hline & Too long & 06 \\
\hline \multirow[t]{2}{*}{ Sitemap } & Present & 00 \\
\hline & Not present & 64 \\
\hline \multirow[t]{2}{*}{ Robot.txt } & Present & 00 \\
\hline & Not present & 64 \\
\hline Broken links & Present & 11 \\
\hline
\end{tabular}

For experimental purpose after setting up the Google analytics account, we have observed the traffic to the website for 30 days. Initially the average traffic to the website was approximately 5 visitors in a month. Even though their user interface looks good from usability point of view but from search engine point of view it was not apt. There were so many structural lacunas in it. Thus in order to make the website user friendly we ask all the 64 students to first finalised the keyword for the webpages with the criteria that for each page they have to choose minimum four non repetitive, unambiguous keywords. After that we ask them to perform the content, structure and link optimization. Table II shows the observations with respect to various parameters before implementing SEO strategy.

From the table II it is clear that, code of all the student need to be change as per the SEO guidelines. We have used various SEO tools to analyse the webpages, then according to the recommendation of tools; students have done changes in code and again it is submitted to the tool to ensure all the recommended changes has been address properly or not. The student have designed stitemap.xml and robot.txt and uploaded in root directory of hosting domain account. The average keyword density for all sites is around 3.4. The plagiarism for web page contents was in the range of $8 \%-14 \%$. Student have either repaired or removed the broken link. The whole process took approximately 20 hours to complete the entire task. After that the google analytics report is analysed and observed that there is a significant rise in the traffic to the website. As mentioned earlier before SEO implementation the average traffic was approximately 5 visitors per month, which then raised to approximately 69 visitors per week. On an average about $93 \%$ traffic coming to the websites is from the desktop system and rest of the traffic is from the mobile devices. The interesting fact that we observed is $82 \%$ of total website got the traffic from other countries like USA, Germany, Russia etc. Maximum percentage of visitors is through the organic search using the Google search engine. High bounce rate is still the concern and need to work upon it in order to avoid it. 


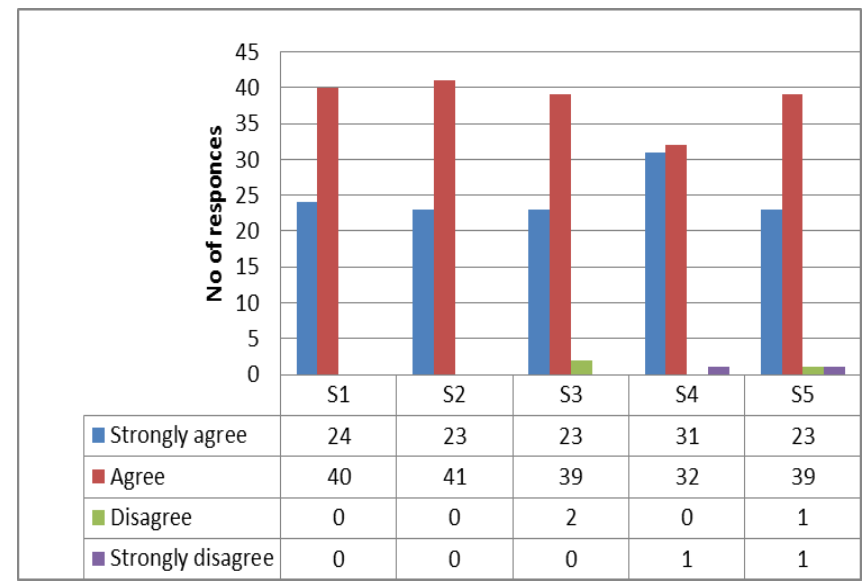

Fig.2. Perception on Course outcome

To analyse the student's perception on the achievement of course outcome feedback was taken. Following statements were given to them.

- S1: Through the experiment carried out by me I am able to apply search engine optimization essentials covering aspects of on-page and off-page optimization to web page

- S2: Through the experiment carried out by me I am able to summarize factors influencing search engine optimization

- S3: Through the experiment carried out by me I am able to state how to measure performance of web site

- S4: The tools which are used for SEO optimization give better visual experience to clear the concept and get better result

Student has to give their views about each statement by selecting appropriate option like strongly agree, agree, disagree, and strongly disagree. Fig. 2 gives feedback statistics from which it can be clearly seen that more than $95 \%$ students agreed that course outcomes are achieved successfully.

In the similar way, perception of students on experiential learning methodology is represented through the feedback taken for statement ES1-ES3.

- ES1: Experiential and collaborative learning opportunities found to be enjoyable.

- ES2: Experiential learning has enhanced the understanding of the concept covered in this course.

- ES3: Through the experiential learning I got knowledge of SEO compatible web development.

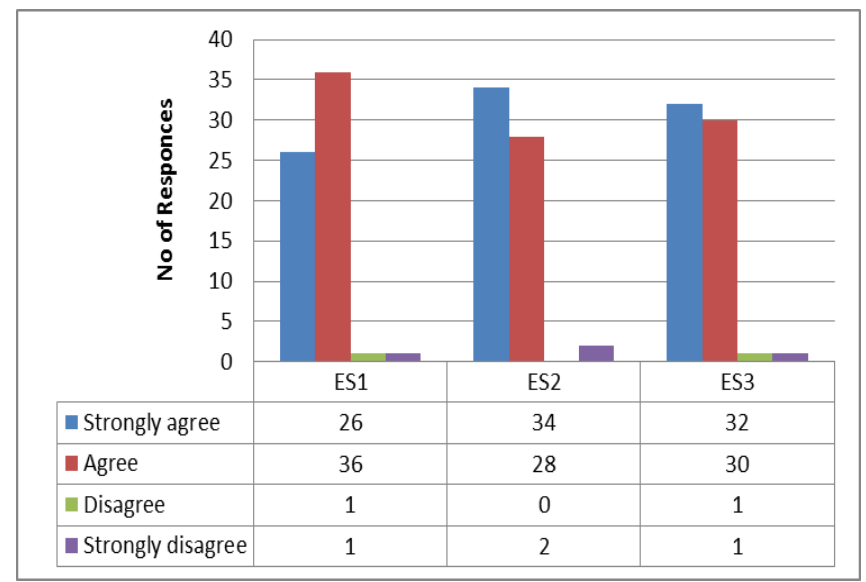

Fig.3. Perception on Experiential Learning

Statements CS1-CS3 are used to get the perception of students on collaborative learning.

- CS1: Presentation and discussion carried out in the end of lab session helped to summarize the complete SEO process. 
- CS2: During the discussion, I came across alternate tool/ technique through which I can achieve the improve the SEO strategy.

- CS3: Presentations help me to improve my communication skill.

- CS4: Post presentation discussion was helpful and interesting.

- CS5: Learning through discussion motivated us to learn from each other's experience and lead to in depth understanding of the concept.

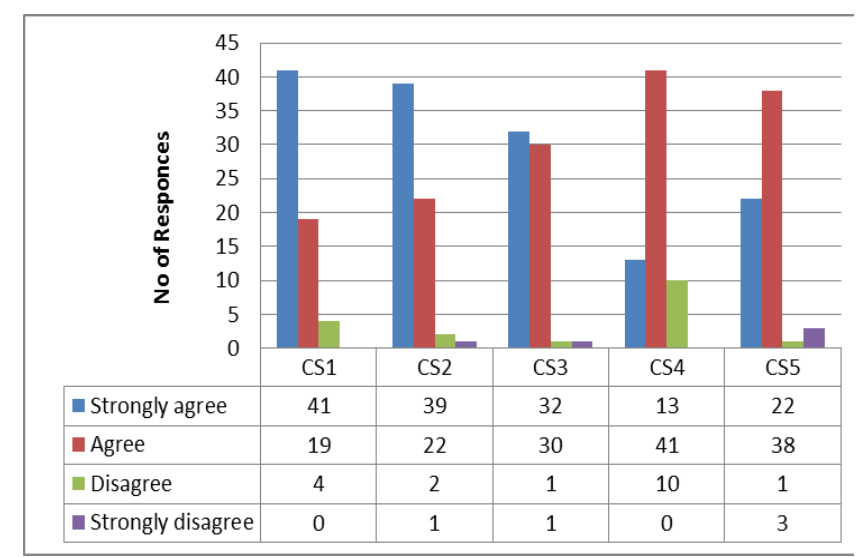

Fig.4. Perceptions on Collaborative Learning

From figure 3, we can conclude that experiential learning has proven as an effective way to get thorough knowledge of the concept and gives real time experience about where one is making mistake and how to rectify it. As depicted in fig 4, few students did not find the discussion in collaborative leaning as an effective way of getting knowledge. But overall we got satisfactory feedback stating the effectiveness of the technique.

To summarise the finding of our study, let us consider the research question again. The first research question is : Is there need of implementation of SEO technique for better visibility of website? The table II states the improvements done in the website and as a result we have observed the increase in the traffic coming to the website. It proves that the visibility of the website is improved substantially and that is why we are getting traffic organically.

The second research question is : What is the impact of experiential learning and collaborative learning techniques on concept acclimatization by the student of technological background? From the feedback given by the students and based on the observation of instructor, it can be concluded that the experiential learning and collaborative learning techniques are proved to be effective. The major reason behind that is, here student have learned the concept and implemented it to check the effectiveness of it. Also collaborative learning has provided a platform where students came across various possible problem and solution to solve it. This ultimately helps them to improve their knowledge

\section{Conclusion}

In this paper we have discussed the use of experiential learning for the subject of Search Engine Optimization which falls in Information Technology discipline. Through experiential learning student have actually implemented the basic search engine optimization techniques and observed the significant improvement in the website traffic and got traffic from all over the globe. Here we have considered the keyword optimization, content optimization and structure optimization to the basic level only. In link optimization we concentrated on removal of backlinks and checking the link quality. As an extension to this collaborative leaning techniques is implemented which includes presentation by student about what he did in experiential leaning followed by discussion? This kind of discussion proves to be little bit time consuming and effort taking form instructors point of view but when it comes to the benefits to the students; it is worth doing. The discussion made students to think about all other possibilities and avenues to solve similar kind of issues. This ultimately broaden the thinking panorama hence improved the problem solving capacity. From the analytical results of website traffic, it can be concluded that students have actually designed the website as per the industry standard and in future they can surely serve the industry in better way. To support the instructor's observation we have taken the feedback on students perception in three categorise viz. Achievement of course outcome, experiential learning technique and collaborative learning techniques. In all cases, more than $90 \%$ students have given positive feedback on all the questions. This proves that student themselves have felt the worth of these techniques in improving their understanding about the topic. 


\section{References}

[1] John I Jerkovic, "SEO Warriors", O'Reilly Media; $1^{\text {st }}$ edition, 2009

[2] Dipti Pawade, Avani Sakhapara, "First Step towards Search Engine Optimization" First edition, LAP LAMBERT Academic Publishing (May, 2018), ISBN- 978-613-9-83042-8.

[3] Eric Enge, Stephan Spencer, Jessie Stricchiola, Rand Fishkin, "The Art of SEO: Mastering Search Engine Optimization", O'Reilly Media; 2 edition, 2012

[4] Mills, Julie, David Treagust. 2003. "Engineering Education - Is Problem-Based or Project-Based Learning the Answer?" Australasian Journal of Engineering Education 3 (2): 2-16. doi:10.1108/13552540210420989.

[5] Biggs, John, and Catherine Tang. 2011. Teaching for Quality Learning at University. Teaching for Quality Learning at University. 4th editio. Berkshire, UK: Society for Research into Higher Education \& Open University Press.

[6] Padmashree Desai ; Achyut Bhandiwad ; Ashok S. Shettar "Impact of Experiential Learning on Students' Success in Undergraduate Engineering"

[7] Kolb, David A. 1984. "Experiential Learning: Experience as The Source of Learning and Development." Prentice Hall, Inc., no. 1984: 20-38. doi:10.1016/B978-07506-7223-8.50017-4.

[8] Ayob, Afida, Aini Hussain, Mohd Marzuki Mustaf, and Muhd Fauzi Aminuddin Shazi Shaarani. 2011. "Nurturing Creativity and Innovative Thinking through Experiential Learning." Procedia - Social and Behavioral Sciences 18: 247-54. doi:10.1016/j.sbspro.2011.05.035.

[9] Verner, I.M., and E. Korchnoy. 2004. "Experiential Learning through Designing Robots and Generating Motion Behaviors." Proceedings World Automation Congress, 2004. 15 (4): 758-65. doi:10.1109/WAC.2004.185192.

[10] Kosnik, R. D., Tingle, J. K., \& Blanton, E. L., III. (2013). Transformational learning in business education: The pivotal role of experiential learning projects. American Journal of Business Education, 6(6), 613-630.)

[11] Nguyen Van, Hanh \& Hợp, Nguyễn. (2017). Experiential Learning Projects in Engineering Education.

[12] Antonio L.Leal-Rodríguez, GemaAlbort-Morantb, "Promoting innovative experiential learning practices to improve academic performance: Empirical evidence from a Spanish Business School", Journal of Innovation \& Knowledge, Volume 4, Issue 2, April-June 2019, Pages 97-103

[13] B.M. Burke, Experiential professional development: A model for meaningful and long-lasting change in classrooms Journal of Experiential Education, 36 (3) (2013), pp. 247-263

[14] Clark, Robert \& Threeton, M.D. \& Ewing, John. (2010). The Potential of Experiential Learning Models and Practices In Career and Technical Education \& Career and Technical Teacher Education. Journal of Career and Technical Education. 25. 46-62. $10.21061 /$ jcte.v25i2.479.

[15] Nooghabi, SN., Iravani H., Fami HS. [2011]. A study on present challenges on experiential learning of university students [University of Tehran, The Colleges of Agriculture and Natural Resources, Iran]. Procedia Social and Behavioral Science [15] pp. 3522-3530.

[16] Suckarieh, G. and Krupar, J. [2005]. "Leadership and Teamwork Education for Engineering and Technology Students: An Experiential Learning and Community Service Approach," in ASEE Annual Conference \& Exposition.

[17] Yadav, A., Subedi, D., Lundberg, M.A. and Buntin, C.F. [2011]. "Problem-based Learning: Influence on Students' Learning in an Electrical Engineering Course," Journal of Engineering Education, vol. 100, no. 2, pp. 253-280.)

[18] Osagiede, A., Cox, M.F. and Ahn, B. [2013]. "Purdue University's Engineering Leadership Program: Addressing the Short-fall of Engineering Leadership Education," in ASEE Annual Conference \& Exposition.

[19] Albdeli, YM., Frank B. [2005]. A Problem Based/Experiential Learning Approach to Teaching Maintenance Engineering. Proceedings of the 2005 ASEE. AaeE 4th Global Colloquium on Engineering Education. Australasian Association for Engineering Education.

[20] C. C. Tseng. [2013]. Connecting Self-directed Learning with Entrepreneurial Learning to Entrepreneurial Performance. International Journal of Entrepreneurial Behavior dan Research, 19 [4], 425- 446.

[21] Dumiyati. [2015]. Pendekatan Experiential learning dalam Perkuliahan Kewirausahaan di Perguruan Tinggi untuk Menghadapi Asean Economic Community [Suatu Kajian Teoretis]. Prosiding Seminar Nasional Profesionalisme Pendidik dalam Dinamika Kurikulum Pendidikan di Indonesia pada Era MEA, hlm. 87- 97, Yogyakarta: FE Universitas Negeri Yogyakarta.

[22] Stephanus Fajar Pamungkas, Indah Widiastuti, and Suharno "Kolb's experiential learning for vocational education in mechanical engineering: A review" AIP Conference Proceedings 2114, 030023 (2019); https://doi.org/10.1063/1.5112427

[23] Mosley, P., Ardito, G., \& Scollins, L. (2016). Robotic cooperative learning promotes student STEM interest. American Journal Of Engineering Education, 7(2), 117-128.

[24] Jansen, A. (2012). Developing productive dispositions during small-group work in two sixth-grade mathematics classrooms: Teachers' facilitation efforts and students' self-reported benefits. Middle Grades Research Journal, 7(1), 37-56. Retrieved from http://pearl.stkate.edu/docview/1458788304?accountid=26879

[25] Zhu C. (2012). Student Satisfaction, Performance, and Knowledge Construction in Online Collaborative Learning. Educational Technology \& Society, 15 (1), 127-136.

[26] Leite Maria C. (2009). The impact of cooperative learning in English language learners' academic achievements

[27] Olga V. Sumtsova, Tatiana Yu.Aikina, Liudmila M. Bolsunovskaya, "Collaborative Learning at Engineering Universities: Benefits and Challenges"

[28] Mark Guzdial, Pete Ludovice, Matthew Real, Tom Morley, Karen Carroll, Akbar Ladak, "The challenge of collaborative learning in engineering and math"

[29] Trespalacios, J., Chamberlin, B., \& Gallagher, R. R. (2011). Collaboration, engagement \& fun: How youth preferences in video gaming can inform 21 st century education. TechTrends, 55(6), 49-54. doi:http://dx.doi.org.pearl.stkate.edu/10.1007/s11528011-0541-5

[30] https://analytics.google.com/analytics/web/ 
[31] C. Zhu and G. Wu, "Research and Analysis of Search Engine Optimization Factors Based on Reverse Engineeing", Third International Conference on Multimedia Information Networking and Security, China, 2011, pp. 225-228.

[32] https://moz.com/

[33] https://kwfinder.com/

[34] https://www.semrush.com/

[35] https://ads.google.com/intl/en_in/home/tools/keyword-planner/

[36] M. Cui and S. Hu, "Search Engine Optimization Research for Website promotion", International Conference of Information Technology, Computer Engineering and Management Sciences, Chaina, 2011, pp. 100-103

[37] V. N. Gudivada, D. Rao, and J. Paris, "Understanding Search-Engine Optimization," Computer, vol. 48, no. 10, pp. 43-52, 2015.

\section{Author's Profile}

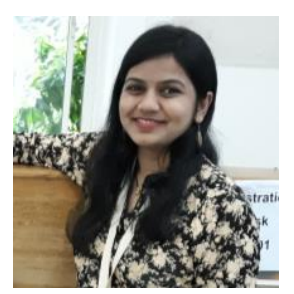

Dipti Yogesh Pawade received B.E. degree in Computer Science and Engineering from Sant Gadge Baba University in 2009 and M.E. degree in Embedded System and Computing from G. H. Raisoni College of Engineering, Nagpur in 2012. Since 2012 she is an Assistant Professor in the Department of Information Technology at K J Somaiya College of Engineering, Vidyavihar, Mumbai. Her interest includes Machine learning, Web Security, and Web Application Development.

How to cite this paper: Dipti Yogesh Pawade, " Analyzing the Impact of Search Engine Optimization Techniques on Web Development Using Experiential and Collaborative Learning Techniques", International Journal of Modern Education and Computer Science(IJMECS), Vol.13, No.2, pp. 1-10, 2021.DOI: 10.5815/ijmecs.2021.02.01 